\title{
Course Setting and Optimization of Public Mathematics in Local Application-Oriented Universities - Taking Sichuan University of Arts and Science as an Example
}

\author{
Rong Hu \\ School of Mathematics, Sichuan University of Arts and Science, Dazhou, China \\ Email: 85194136@qq.com
}

How to cite this paper: $\mathrm{Hu}, \mathrm{R}$. (2021) Course Setting and Optimization of Public Mathematics in Local Application-Oriented Universities-Taking Sichuan University of Arts and Science as an Example. Open Access Library Journal, 8: e7198.

https://doi.org/10.4236/oalib.1107198

Received: January 29, 2021

Accepted: February 5, 2021

Published: February 8, 2021

Copyright (c) 2021 by author(s) and Open Access Library Inc.

This work is licensed under the Creative Commons Attribution International License (CC BY 4.0).

http://creativecommons.org/licenses/by/4.0/

\begin{abstract}
As an important compulsory basic course for relevant majors in universities, public mathematics is an important part of the course system in the talent training program of local application-oriented universities. From the perspective of the construction of local application-oriented high-level universities, this paper takes Sichuan University of Arts and Science as an example, investigates and analyzes the current conditions of the course of public mathematics, and gives a reasonable optimization scheme of the course system of public mathematics combined with optimization ideas and improvement direction.
\end{abstract}

\section{Subject Areas}

Mathematics

\section{Keywords}

Applied University, Public Mathematics, Course System, Setting, Optimization

\section{Introduction}

In the new stage of the construction of local application-oriented high-level universities, there are new requirements for the setting and optimization of the course system of public mathematics. As a professional basic course in under- 
graduate universities, the series of courses of public mathematics is a compulsory course for students who major in economic management and science and engineering. The offering of these courses can help to develop students' logical thinking ability, improve their innovation ability, and lay a solid foundation for the study of subsequent professional courses. At present, many local colleges and universities are in a new stage of the transformation to application-oriented universities. How to develop the course offering system of public mathematics suitable for the development of the new conditions under the premise of great differences in the foundation of students and different demands for public mathematics knowledge of the cultivation of professional talents is a problem urgently to be solved. For the setting of the course system, teaching content, teaching methods and other issues of public mathematics, many scholars at home and abroad have done research, made reforms [1]-[8] and achieved certain results, but no existing method can be applicable to the actual conditions of our university. Therefore, this paper will analyze and study the current conditions of the setting of the course system of public mathematics according to the specific conditions of our university and develop a more reasonable and optimized course offering program.

\section{Investigation and Analysis on the Current Conditions of the Course Offering of Public Mathematics in Our University}

\subsection{Current Conditions of Course Offering}

The course of public mathematics mainly includes Advanced Mathematics, Linear Algebra, and Probability Theory and Mathematical Statistics. At present, 8 Level-2 schools and 27 majors offer these courses, including the School of Mathematics, School of Ecotourism, School of Architectural Engineering, School of Politics and Law, School of Financial and Economic Management, School of Teacher Education, School of Chemistry and Chemical Engineering, School of Intelligent Manufacturing, and School of Health Care. According to the 2016 edition of talent cultivation plan, the current conditions of course offering of each school and major is shown in Table 1.

As can be seen from Table 1, in the university 8 schools and 27 majors offer Advanced Mathematics, 5 schools and 20 majors offer Linear Algebra, and 5 schools and 15 majors offer Probability Theory and Mathematical Statistics. By course, the conditions of the course offering of each major are shown in Table 2.

As can be seen from Table 2, the three courses of Advanced Mathematics, Linear Algebra, and Probability Theory and Mathematical Statistics are different in different schools and majors.

From the above survey information, it can be seen that the current conditions of the course offering of public mathematics in our university are relatively complex. Many schools and majors offer the course, the numbers of class hours are different and the semesters of the course offering are inconsistent. 
Table 1. Conditions of the course offering of public mathematics (by school and major).

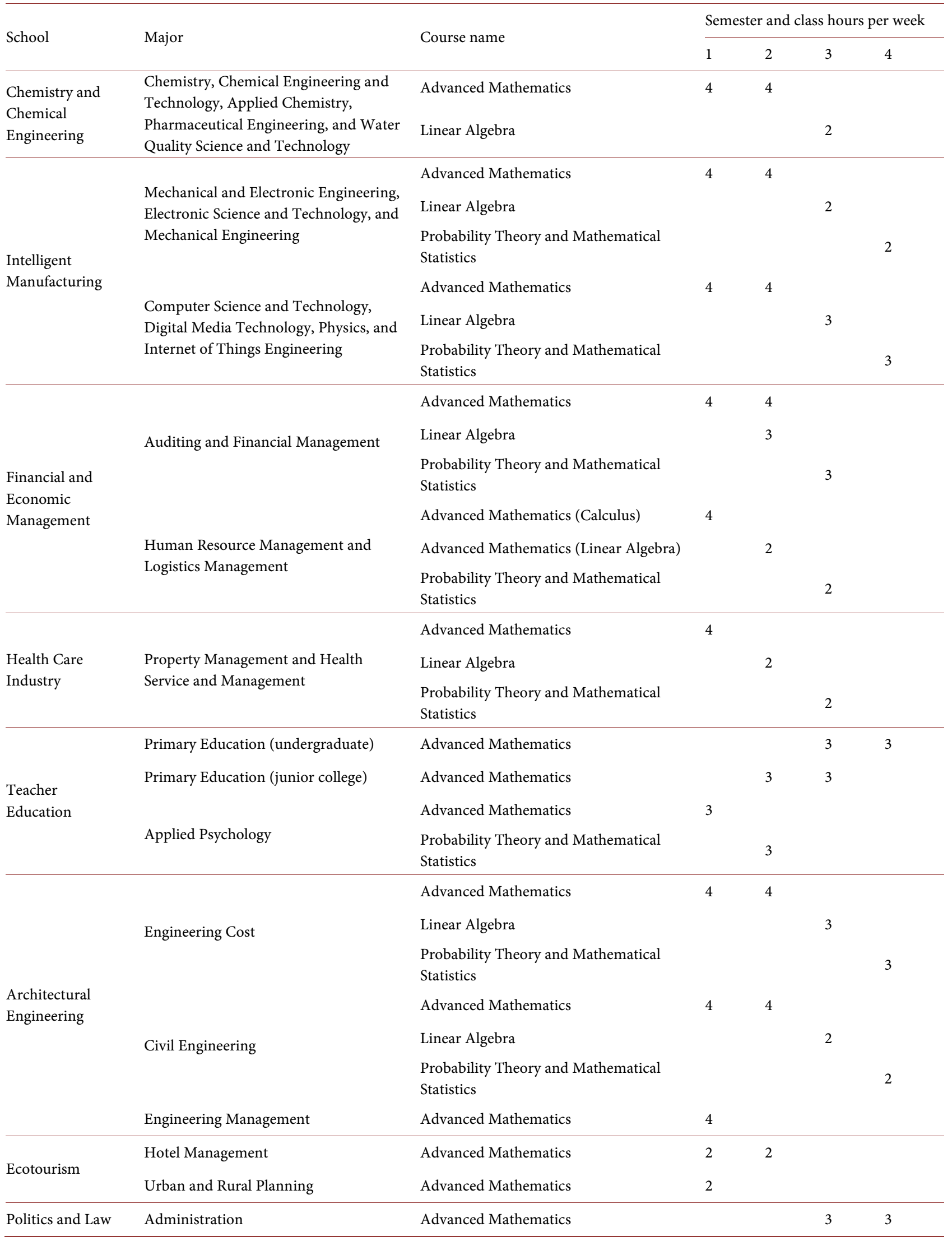


Table 2. Conditions of the course offering of public mathematics (by course).

\begin{tabular}{|c|c|c|}
\hline Course name & School & Class hours \\
\hline \multirow{4}{*}{ Advanced Mathematics } & Chemistry and Chemical Industry, Intelligent Manufacturing and Architectural Engineering & $4+4$ \\
\hline & Financial and Economic Management and Health Care Industry & $4+4 / 4$ \\
\hline & Teacher Education & $3+3 / 3$ \\
\hline & Politics and Law and Ecotourism & $3+3 / 2+2 / 2$ \\
\hline \multirow{2}{*}{ Linear Algebra } & Chemistry and Chemical Industry, Intelligent Manufacturing and Architectural Engineering & $2 / 3$ \\
\hline & Financial and Economic Management and Health Care Industry & $3 / 2$ \\
\hline Probability Theory and & Teacher Education, Intelligent Manufacturing and Architectural Engineering & $3 / 2$ \\
\hline Mathematical Statistics & Financial and Economic Management and Health Care Industry & $3 / 2$ \\
\hline
\end{tabular}

\subsection{Main Problems Encountered in the Current Stage}

In order to further understand the teaching and learning of the course of public mathematics, the Teaching and Research Office of Public Mathematics of the School of Mathematics repeatedly made the in-depth research on each school offering the course, and organized the forum of commissaries in charge of studies and student representatives to fully understand the teaching information about the course of public mathematics. Combined with the course offering of each major in the 2016 edition of the talent cultivation plan, the main problems existing in the current course offering of public mathematics and the teaching process are summarized as follows:

First, the setting of class hours is not standardized and reasonable enough. On the one hand, the semesters of the course offering are inconsistent. As a basic course of different majors, the course of Advanced Mathematics generally should be offered in two semesters from the first semester of the freshman year. However, due to the arrangement of other courses, in some majors this course is offered in the second and third semester or the third and fourth semester. The courses of Linear Algebra and Probability Theory and Mathematical Statistics are offered in the second, third and fourth semesters. On the other hand, the class hours of similar majors in the same subject and the same school are not consistent, which will affect the teaching arrangement of basic courses when the major develops into the class enrollment in the future, For example, after the major is reselected, students of the same major may have different credits.

Second, the number of class hours of some majors is small. If the textbook compiled by the Mathematics Department of Tongji University is used for the course of Advanced Mathematics, it will take 128 class hours to complete the basic teaching content. It can be offered in two semesters with 4 class hours per week. If the textbook of Economic Mathematics-Calculus compiled by $\mathrm{Wu}$ Chuansheng is used, it will at least need 96 class hours. Only 64 class hours in some majors such as Property Management and Health Service and Management, which cannot meet the basic teaching needs. In addition, due to the richness of content and the difficulty of the course itself, if the number of class hours of the course of Probability Theory and Mathematical Statistics is too small, it 
will not be good for the teaching arrangement of teachers and it cannot meet the subsequent learning needs of students.

Third, different majors have different requirements for teaching content. Through the investigation and survey, it is found that the requirements for the teaching content of Public Mathematics have great differences in different majors. For example, the School of Architectural Engineering, the School of Chemistry and Chemical Engineering, the School of Intelligent Manufacturing, the School of Financial and Economic Management and the School of Health Care Industry have higher requirements for mathematical knowledge. Combined with the needs of majors and students' development, these five schools hope to consolidate students' mathematical foundation, promote the subsequent study of professional courses, and provide guidance for students taking part in the postgraduate entrance exams. The School of Chemical Engineering proposes that a lot of knowledge of functional calculus is involved in the chemical professional courses, and teachers are required to strengthen the teaching of derivation and quadrature of function of one variable and function of several variables and the related knowledge of the differential equation of first order. The Major of Logistics Management of the School of Financial and Economic Management proposes to strengthen the teaching of first-order derivative and second-order derivative of function, differential, extreme value, marginal analysis, break-even analysis and other contents. For the Majors of Mechanical and Electronic Engineering, Electronic Science and Technology, Mechanical Engineering and Physics, the School of Intelligent Manufacturing proposes to increase the breadth of the teaching content of advanced mathematics, and requires the introduction of triple integral, Gauss formula, Stokes formula, Fourier series and differential equation. The School of Ecotourism, the School of Political Science and Law and the School of Teacher Education do not have high requirements for mathematical knowledge and focus on the improvement of the mathematical cultural literacy.

\section{Optimization Ideas of the Course Setting}

\subsection{Based on the Transformation and Development of the University Redevelop the Cultivation Objectives}

Local universities have different development orientations, including teaching-oriented university, teaching-and-research-oriented university, application-oriented university, etc. As the basic course serving the later learning of different majors, the course of public mathematics should have different development orientations and teaching objectives and contents [1]. In 2016, our university was identified as the "Experimental Unit of Overall Transformation and Development of Colleges and Universities in Sichuan Province". At present, it is in a critical period of transformation and development. In order to help the university to realize the transformation and development in an all-round way and build into a "high-level application-oriented university with distinctive characteristics and outstanding advantages" as soon as possible, as a basic compulsory course of 27 majors in the university such as science, engineering, economics 
and management, the course of public mathematics must be constructed and optimized. Under the cultivation mode of application-oriented undergraduate talents, in the construction of the course of public mathematics, we should change the phenomenon of paying too much attention to the knowledge system and neglecting the combination of the development orientation of the course and university and students' development needs, rely on the science and technology of the discipline and industry as the main standard, focus on the combination of theory and practice, reconstruct the teaching objectives from the aspects of knowledge and skills, thinking ability and application ability, and develop the mathematical literacy required by application-oriented undergraduate talents for students [3].

\subsection{Integrate the Class Hours Combined with the Professional Cultivation Needs}

According to the relevant guidance documents issued by the university management department and the university, combined with their own professional cultivation requirements, each major should make a talent cultivation plan and arrange the teaching hours of each course. In the setting of the course of public mathematics, there are some phenomena such as insufficient teaching hours, inconsistent class hours of similar majors and inconsistent semesters. If the number of class hours is too small, to complete the teaching task, teachers are likely to provide cramming education, lack the interaction with students and fail to leave any thinking space for students, so that they cannot achieve the objective of developing the mathematical thinking of students. If the semesters and class hours of similar majors are not consistent, it will hinder the course offering after the development into enrollment by discipline in the later stage. Therefore, in the optimization of the course system of public mathematics, we should combine with the professional cultivation needs, integrate the teaching hours by category, appropriately increase the class hours of courses with few class hours, standardize the semester of course offering, and unify the course offering by category.

\subsection{Innovate the Teaching Methods Based on the Effective Teaching Concept}

Based on the reasonable setting of the course system, teachers should innovate the teaching methods based on the effective teaching ideas. Teachers of the course of mathematics generally use the traditional teaching mode in the teaching process, pay attention to the explanation of mathematical knowledge and ignore the formation of mathematical thinking and mathematical application ability of students, which obviously should be changed [4]. First, teachers should change the traditional teaching concept, define the mathematical thought of the course of mathematics in the professional course system, and pay attention to the development of mathematical thinking methods and mathematical application ability; second, they should pay attention to the guidance and improvement of interest in mathematics learning of students, and can establish the relation- 
ship between mathematics knowledge and major with the idea of mathematical modeling, attract students' attention with the help of mathematical history and mathematical stories, and make the mathematics learning more interesting; and finally, in the era of the rapid development of network information technology, they can innovate the teaching methods with the modern educational technology, such as implementing the teaching of "flipped classroom" with the online teaching platform or enriching the traditional classroom teaching with the combination of online and offline teaching methods, which can help with the optimization and implementation of the course system of public mathematics.

\section{Optimization Scheme of the Setting of the Course of Public Mathematics}

Based on the research and analysis of the current conditions of the course setting of public mathematics in our university (Table 3), combined with the existing problems and the improvement direction, the course offering scheme of public mathematics plan is optimized as follows.

i) Unit offering the course: the School of Mathematics.

ii) Course category: professional basic course or professional core course.

iii) Course name: Advanced Mathematics, Linear Algebra and Probability Theory and Mathematical Statistics.

iv) Schools offering the course and suggestions on the classification.

Class A (science and engineering): the School of Intelligent Manufacturing, the School Chemistry and Chemical Engineering and the School of Architectural Engineering.

Class B (economics and management): the School of Financial and Economic Management.

Class C (teacher education): the School of Teacher Education.

Class D (liberal art): the School of the Health Care Industry and the School of Ecotourism.

Note: The schools choose to offer the course in some or all of the majors according to needs of the major.

v) Time of the course offering, class hours and credits.

1. Advanced Mathematics

A. Class B: the first semester, 4 credits and 64 class hours; the second semester, 4 credits, and 64 class hours. 128 class hours in total.

Class C: the first semester, 3 credits and 48 class hours; the second semester, 3 credits and 48 class hours. 96 class hours in total.

Class D: the first semester, 2 credits and 32 class hours; the second semester, 2 credits and 32 class hours. 64 class hours in total.

\section{Linear Algebra}

The third semester, 3 credits (or 2 credits) and 48 class hours (32 class hours).

3. Probability Theory and Mathematical Statistics

The fourth semester, 3 credits (or 2 credits) and 48 class hours (32 class hours). 
Table 3. List of courses offered.

\begin{tabular}{|c|c|c|c|c|c|c|c|}
\hline \multirow{2}{*}{ Course name } & \multirow{2}{*}{$\begin{array}{l}\text { Teaching } \\
\text { category }\end{array}$} & \multicolumn{2}{|c|}{ Credits/Class hours } & \multicolumn{4}{|c|}{ Semester and class hours per week } \\
\hline & & Credits & Class hours & 1 & 2 & 3 & 4 \\
\hline \multirow{3}{*}{ Advanced Mathematics } & Class A and B & 8 & 128 & 4 & 4 & & \\
\hline & Class C & 6 & 96 & 3 & 3 & & \\
\hline & Class D & 4 & 64 & 2 & 2 & & \\
\hline Linear Algebra & & $3 / 2$ & $48 / 32$ & & & $3 / 2$ & \\
\hline Probability Theory and Mathematical Statistics & & $3 / 2$ & $48 / 32$ & & & & $3 / 2$ \\
\hline
\end{tabular}

Note: 1 . The majors should choose to offer three, two or one course according to needs of the major.

2. For Linear Algebra and Probability Theory and Mathematical Statistics, we should choose to set 3 credits or 2 credits according to the needs. It is suggested that the credits of different majors under the same discipline should be consistent.

vi) Management and assessment methods.

In order to fully implement the principle of "classified guidance and individualized teaching" in teaching, meet the actual needs of individualized teaching and achieve the cultivation objectives of different majors, the classified and unified management is implemented for the course of public mathematics in the whole university. For the same category, the textbook, teaching program, examination program, teaching progress, test questions and examination time should be the same.

The assessment method consists of the assessment at ordinary times and the final examination. The usual performance accounts for $30 \%$ and the final examination result accounts for $70 \%$. At present, the final examination is still in the form of written closed-book examination, and it will gradually change to computer examination when the conditions permit.

\section{Conclusions}

The paper is supported by two funds (see the end of the article). It is the main result of the project: Course Setting and Optimization of Public Mathematics in the Sichuan University of Arts and Science. On the other hand, it is also some achievements of curriculum reform of Advanced Mathematics, which is the Demonstration Course Project of "Ideological and Political Theories Teaching in All Courses".

There is still a lot of work to do in the teaching reform of the course of public mathematics. We still need to continuously make efforts and move forward. As the follow-up practical work of this paper, we will take the making of the 2020 edition of the talent cultivation plan of the university as an opportunity, and help with the reasonable making of the new edition of the talent cultivation plan of different majors based on the optimization plan of the course setting of public mathematics. Under the guidance of the talent cultivation plan, according to 
different needs of students of different majors, we will further optimize the teaching content, teaching methods, assessment methods and other problems of the course of public mathematics, lay a mathematical foundation for the cultivation of talents of different majors, and contribute the mathematical strength to achieve the objective of a high-level application-oriented university as soon as possible.

\section{Fund Project}

Educational Teaching Research and Reform Project of Sichuan University of Arts and Science (2020JZ043); Demonstration Course Project of "Ideological and Political Theories teaching in All Courses" of Sichuan University of Arts and Science (2020kcsz008).

\section{Conflicts of Interest}

The author declares no conflicts of interest regarding the publication of this paper.

\section{References}

[1] Tao, Y., Zhang, L. and Luo, L. (2016) Teaching Reform and Practice of the Courses of Public Mathematics in Local Universities. Education Exploration, No. 9, 89-91.

[2] Xiang, M. and Sun, L. (2019) Research on the Reconstruction and Reform of the Course System of Public Advanced Mathematics in Local Application-Oriented High-Level Universities. Journal of Science of Teachers' College and University, 39, 46-49.

[3] Gou, L., Fan, Y. and Wang, Y. (2016) The Construction of the Courses of Public Mathematics under the Cultivation Mode of Application-Oriented Undergraduate Talents. Journal of Heihe University, No. 1, 64-66.

[4] Zhang, X. and He, Z. (2012) Reform and Design of the Course System of Public Mathematics under the Mode of Category Teaching of the Major. University Mathematics, 28, 10-14.

[5] Zu, L., Yang, J. and Wang, P. (2019) The Reform of the Content and Assessment Method of the Course of Public Mathematics-Take the Hainan Normal University as an Example. Journal of Hainan Normal University (Natural Science Edition), 29, 112-115.

[6] Chen, F. (2018) Research on the Course Adjustment and Reform of Applied Undergraduate Education. Thesis, East China Normal University, Shanghai.

[7] Wang, Q. (2018) Exploration on the Reform of the Course System of Advanced Mathematics in Colleges and Universities. Journal of Higher Education, No. 18, 135-137.

[8] Xie, X. and Wu, Y. (2019) Strategies and Practice for Improving the Teaching Quality of the Public Course of Mathematics-Take the Northwest A\&F University as an Example. China Forestry Education, 37, 59-62. 